\title{
Leghorn Chicken
}

National Cancer Institute

\section{Source}

National Cancer Institute. Leghorn Chicken. NCI Thesaurus. Code C77098.

A small, commonly white-colored breed of poultry that is renowned for its ability to produce up to 300 chalk white eggs per year. The fully-grown leghorn chicken averages 3-6 pounds in weight and is characterized by being noisy, flighty, and easily excited. The leghorn has a lifespan of 5-11 years in the wild. In pre-clinical research, the leghorn is a consistent provider of eggs for embryonic, angiog enic, and vasculogenic research. 